\title{
Arbor
}

\section{Breves notas sobre una colección de arte privada}

\section{Luis Guillermo Perinat y Elio}

Arbor CLXV, 649 (Enero 2000), 77-81 pp.

En los confines del viejo Madrid se encuentra una casa cuya fachada, aunque algo adomada no llama especialmente la atención del viandante. Es un edificio construido en la segunda mitad del siglo pasado y que guarda mucho el estilo de las demás construcciones de cierto nivel de su tiempo.

En esa casa se estableció por aquellos años una familia que posiblemente por su trayectoria cosmopolita tenía una sensibilidad especial para todo lo artístico. Durante toda la época que va desde finales del reinado de Isabel II hasta principios del de Alfonso XIII, ya fuera por la inestabilidad de la política, por la debilidad del poder adquisitivo de los españoles y también, todo hay que decirlo, por la falta de cultura de la mayoría de nuestros compatriotas, incluso de aquellos que por su nivel social debieran haber tenido la suficiente educación, resultaba posible adquirir relevantes obras de arte en condiciones francamente favorables.

Fue, pues, durante ese período cuando se formó la mayoría de la colección de pinturas, esculturas, tapices, porcelanas y mobiliario a que me voy a referir aunque ciertamente otras obras de arte llegaron a la casa por distintas procedencias, ya fuera por herencias o matrimonios posteriores.

El caso es que allí, en esa casa, ese conjunto de obras de arte han formado parte de la misma, sin que se hayan producido apenas cambios en su colocación desde hace ya casi un siglo y medio.

Justo antes de la Guerra Civil, cuando tanto patrimonio artístico se destruyó o se perdió, la suerte hizo que la casa a la que nos estamos refiriendo fuera alquilada para embajada de un país hispanoamericano, habiendo encontrado en ella refugio, durante esos años de odios encon- 
trados, primero cientos de personas pertenecientes al bando nacional y luego ya terminada la contienda, un grupo de dirigentes del lado republicano. La afortunada circunstancia de la extraterritorialidad diplomática permitió que, además de que varios cientos de personas salvaran sus vidas o su libertad, las obras de arte que con tanto esmero se habían llegado a reunir permanecieran intocadas en sus respectivos lugares, y así han quedado prácticamente igual hasta el día de hoy.

En las casas residenciales españolas del siglo pasado las alturas de techo eran bastante más altas que en las de la actualidad. Ello hacía posible que en muchas de ellas se siguiera una tradición que nos viene muy de antiguo. Al colgar tapices en los altos y amplios paneles se les daba un aspecto más caliente y acogedor. $\mathrm{Y}$ así las cosas, a la casa a la que yo me estoy refiriendo vino a parar una colección de tapices procedente de un viejo palacio de Zaragoza. Consiste en una serie de ocho tapices tejidos en el siglo XVII en Bruselas, siguiendo diseños de David Teniers, el joven. Dos de ellos hacen pareja y son de grandes dimensiones, representando uno de estos la noche y el otro el día. En el primero la figura central es una diosa alada, posiblemente Eos, aunque más probablemente Nyx, ya que esta divinidad personificó las tinieblas, atribuyéndosele un culto en el que se practicaban sacrificios de ovejas negras, gallos y búhos. Y en este tapiz vemos a la Diosa sentada en un trono de ruedas bajo un firmamento de estrellas, rodeada de un círculo de angelotes, teniendo en su parte inferior y a modo de ofrenda ya sumidos en la oscuridad, precisamente a búhos y a murciélagos.

En cambio en el que representa el sol, aparece Helios en todo su esplendor con un halo de rayos dorados sobre su cabeza teniendo todo el conjunto una gran luminosidad. Se encuentra Helios de pie en su carro, con un arco en la mano, un haz de fleechas a su espalda y arrastrado por un par de hermosos caballos que parecen materialmente escapar de la tela. Al igual que su pareja, la noche, queda rodeado por un círculo de angelotes.

Formando parte de esta misma colección de Teniers, son los cuatro tapices representando los continentes terráqueos. Cada uno de los continentes viene representado por mujeres jóvenes y bellas.

Europa está coronada y sujeta en una de sus manos un templete griego, pero sobre el cual ha sido colocado una cruz. Todo un símbolo. Tras ella asoma en un entorno fértil la cabeza de un hermoso caballo. Asia está ofreciendo incienso al espectador y a sus espaldas se va alejando hacia un páramo un dromedario. África, por cierto una hembra sensual y pechugona, lleva a manera de sombrero una cabeza de elefante 
y ¡como no! frente a ella se sitúa un león dominando el paisaje. Por último, América queda representada por una joven india con el clásico tocado de plumas rojas y azules y a la que no parece afectar la presencia cercana de un inmenso caimán. A la originalidad de estos motivos y a la forma en que han sido concebidos cada uno de estos cuatro ejemplares, hay que añadir como mérito la vivacidad de sus colores, sobre todo en los rojos y en los azules y la buena conservación de los mismos.

Vayamos ahora a los cuadros y empecemos por los maestros españoles. Nos detenemos en primer lugar ante «La Virgen de la leche» de El Greco, un cuadro de la última época del pintor. Las figuras representadas: la virgen y el niño (para modelo de la virgen, por cierto, el pintor utilizó a su mujer) parecen estar flotando en el cielo en un fondo de nuubes de tonos azules y blanquecinos. El toque místico tan propio de las obras sobresalientes de este maestro greco-toledano es pues aquí su nota predominante.

En la misma sala, encontramos la «Sagrada Familia» de Zurbarán. Las seis figuras que componen el cuadro son de tamaño natural. Curiosamente, la que reviste mayor importancia desde el punto de vista pictórico, no es el niño Jesús ni tampoco la virgen, ni siquiera San José, sino un San Juan Bautista de niño, arrodillado, situado en primer plano que está ofreciendo frutas en un canastillo a la Sagrada Familia. Desde este primer plano, se van alejando en diagonal las otras figuras, dándole al cuadro una especial perspectiva y una técnica muy adelantada para su época. San Juan tiene sobre su hombro desnudo, echada, una capa cuyos pliegues no pueden menos que recordarnos los que con excepcional maestría supo tantas veces reproducir este pintor en frailes y santos.

Muy distintos de estos cuadros de motivo religioso son tanto el retrato de Cean Bermúdez de Goya como el de las dos niñas atribuido desde siempre en la familia a Claudio Coello. Es este último un conjunto de enorme elegancia y delicadeza. Las dos niñas han sido vestidas con elegantes trajes bordados color granate, lo que las hace destacar sobre el fondo oscuro de la estancia en que se encuentran. Se contemplan una a la otra con sorpresa sin duda por el pajarito que una de ellas sostiene en una de sus manos. Tiene el cuadro a ambos lados sendos anagramas y aunque han sido estudiados repetidamente, no se ha conseguido hasta ahora descifrar quienes son sus atractivas protagonistas.

$\mathrm{Y}$ como retrato sobresaliente, nos tenemos que referir al que sin duda dadas las especiales circunstanaus de amistad que le unía con 
el modelo, pintó Goya a Cean Bemúdez. Este famoso crítico de arte y gran coleccionista, está sentado - casi tumbado- mirando de frente al espectador. El calzón corto de una de sus piernas, con su pantorrilla y el pie calzado con zapato de hebilla, nos dan la impresión de estar saliéndose del lienzo. Como contraste la cabeza empelucada está echada hacia atrás con profunda expresión en la mirada a la que sin duda quiso el pintor imprimir el signo de la inteligencia. Nos encontramos pues ante una magnífica obra ejecutada cuando el genial maestro de Fuendetodos estaba en toda su plenitud.

Acompañan a estas pinturas otras de la escuela flamenca de no menos interés. "La resurrección de Lázaro» de Dirck (Dierick) Bouts es una tabla de $75 \times 50 \mathrm{~cm}$. en la que el personaje evangélico mira asombrado, todavía sentado en su sepulcro a un Jesucristo rodeado de diez figuras primorosamente vestidas con atuendos orientales, pero en cuyo fondo se divisa muy anacrónicamente un castillo propio de los Países Bajos de s. XV.

Mucho más sencillo, pero también de gran importancia es el tríptico de Memling, pintado así mismo sobre tablas y en cuyo elemento central se encuentra la virgen con el niño figurando en sus partes laterales dos ángeles que la veneran.

Completaría lo más destacado de esta relación pictórica -que por supuesto no pretende ser exhaustiva- mencionando dos cuadros de Jan Brueghel que hacen pareja, uno de ellos titulado «El fuego», en el que sobresale un volcán en erupción en un entorno algo tétrico y el otro «El aire», que queda representado por unos personajes alrededor de los cuales flota una hojarasca en un vendaval; un San Juan Bautista de Ribera, original de la primera época del Spagnoletto donde aparece el santo con su inseparable cordero; cuatro cabezas de Giovanni Battista Tiépolo en los que retrata, utilizando sus característicos claroscuros a mercaderes turcos tocados con sus clásicos turbantes y cinco paisajes de Pillement, ejecutados unos al óleo y otros al pastel, predominando en todos ellos los tonos azulados. Son estos ejemplares típicos de la escuela francesa de la época, en la que la tendencia por lo bucólico es la nota predominante.

No podemos dejar de mencionar que en la casa formando un conjunto muy vivido con cuadros y tapices se encuentran muebles de época de importancia, así como colecciones de porcelana y cerámica. Algunos de los muebles según tradición familiar proceden del propio Palacio Real como consecuencia de ventas llevadas a cabo en la segunda mitad del siglo pasado, concretamente durante la primera república, cuando la anarquía reinante hizo posible ese tipo de enajenaciones. Entre los 


\section{Breves notas sobre una colección de arte privada}

de mayor relevancia figura un altar de campaña de marquetería estilo Carlos IV y que al parecer perteneció a dicho monarca.

Este altar por haber sido utilizado para celebrar algún matrimonio familiar y también en las ceremonias religiosas durante la Guerra Civil, cuando la casa hacía de embajada, tiene lógicamente un valor sentimental añadido.

$\mathrm{Y}$ al suscitar el valor sentimental que pueden tener las cosas inanimadas, me voy a permitir terminar sacando a colación la historia de dos obras de arte, que si no fuera por esa razón quizá pasarían más inadvertidas. Una de estas es un conjunto grande de porcelana. $\mathrm{Al}$ pie de una columna coronada por Minerva están sentadas cuatro muchachas. Una de ellas está vestida al estilo de la región levantina española y representa la porcelana de Alcora; otra ataviada como una menina, es la representación de la del Retiro; la tercera de morisca, rememora la Hispanoárabe y la cuarta con su traje de campesina valenciana se identifica con la cerámica de Manises. El conjunto en cuestión que es una preciosa alegoría de la porcelana española. Se fabricó para un antepasado de alguién de la familia, y a él va dedicado por haber empleado gran parte de su vida a estudiar y prestigiar la porcena de Alcora. Y de él podemos contemplar un magnífico retrato pintado por Sorolla.

No menos carga afectiva puede tener un estupendo cuadro salido de los pinceles de Álvarez de Sotomayor. En el vemos a una señora ya muy vieja sentada en un sillón alto, frailumo, con un rosario de plata colgado al cuello a modo de collar. A sus pies se encuentra un niño de unos tres años. La señora en cuestión es la que a lo largo de su existencia, por amor al arte, y nunca mejor dicho, reunió gran parte de las obras que se han ido describiendo. El que firma este artículo tiene como uno de los recuerdos más remotos de su infancia y un poco como en una nebulosa, haber posado con su abuela en el estudio de ese gran retratista, autor de preciosas escenas campesinas gallegas y director del Museo del Prado.

Hoy más de setenta años después quiere agradecer a su buena amiga Carmen Rocamora el haberle pedido y el haberle dado ocasión de escribir estas líneas. 